\title{
JUIZADOS ESPECIAIS CÍVEIS: ABORDAGEM HISTÓRICA E PRINCIPIOLÓGICA
}

\author{
Thais Fernanda Silva Rogério, Israel Matheus Cardozo Silva Coutini, Pedro Teófilo de Sá
}

Universidade do Oeste Paulista - UNOESTE, curso de Direito, Presidente Prudente, SP. E-mail: thais_fsr@hotmail.com

\section{RESUMO}

Objetiva o presente estudo a abordar o histórico dos Juizados Especiais Cíveis, de forma a destacar todas as leis que regulamentaram sua criação até a chegada da Lei n 9.099/1995 que o efetivou. No mais, destaca de forma peculiar os princípios norteadores do órgão em questão, enfatizando a finalidade e a aplicação de cada um deles, visando, principalmente, a uma maior contribuição com as atividades de pesquisas no Curso de Direito e a participação dos alunos numa perspectiva científica. O artigo utilizou-se do método hipotético-dedutivo, baseando-se em pesquisas bibliográficas e jurisprudenciais, tendo a intenção de possibilitar a compreensão histórica e principiológica dos Juizados Especiais Cíveis. Os resultados foram persuasivos, eis que foi possível, pelo âmbito elementar e conceitual, observar as grandes influências e importâncias dos Juizados Especiais Cíveis no mundo jurídico atual.

Palavras-chave: Juizados Especiais Cíveis. Histórico. Leis. Princípios. Finalidade.

\section{CIVIL SPECIAL JUDGMENTS: HISTORICAL AND PRINCIPIOLOGICAL APPROACH}

\begin{abstract}
The purpose of this study is to address the history of the Special Civil Courts, in order to highlight all the laws that regulated its creation until the arrival of Law n. 9.099/1995 that made it effective. Moreover, it highlights in a peculiar way the guiding principles of the organ in question, emphasizing the purpose and the application of each of them, and aiming, mainly, a greater contribution with the researches activities in the Course of Law and the participation of the students from a scientific perspective. The article used the hypothetical-deductive method, based on bibliographical and jurisprudential research, with the intention of making possible the historical and principiologic understanding of the Special Civil Courts. The results were persuasive, since it was possible, through the elementary and conceptual scope, to observe the great influences and importance of the Special Civil Courts in the current legal world.
\end{abstract}

Keywords: Special Civil Courts. Historic. Laws. Principles. Goal.

\section{INTRODUÇÃO}

O presente trabalho aborda, inicialmente, a origem dos Juizados Especiais Cíveis e sua posterior regulamentação pela Lei n.o 7.244/84. No mais, destaca previsão na Constituição Federal, em seu artigo 98, I, da criação dos Juizados Especiais e, finalmente, a Lei n.o 9.099/95, de regência própria do órgão em questão, a qual foi incumbida o cumprimento da determinação do mencionado dispositivo constitucional - com a finalidade de amplo acesso à justiça.

Ademais, aborda os princípios norteadores do órgão, quais sejam, oralidade, simplicidade, informalidade, economia processual e celeridade, conforme dispõe o artigo 20 da Lei supracitada, visando à conciliação ou à transação, destacando, ainda, de forma peculiar, a finalidade e a aplicação de cada um deles no âmbito dos Juizados Especiais Cíveis.

Fixadas tais asserções, o objetivo do presente estudo é abordar o histórico e os princípios norteadores dos Juizados Especiais Cíveis.

\section{METODOLOGIA}


O método utilizado na pesquisa foi o hipotético-dedutivo, baseando-se em pesquisas bibliográficas e jurisprudenciais, construindo as bases do trabalho numa interpretação reflexiva e dialética, tendo a intenção de possibilitar a compreensão histórica e principiológica dos Juizados Especiais Cíveis.

\section{DISCUSSÃO}

\section{HISTÓRICO DOS JUIZADOS ESPECIAIS CÍVEIS}

O Juizado Especial estadual originou-se nos Conselhos de Conciliação e Arbitragem, em 1982, no Estado do Rio Grande do Sul, com a finalidade de acabar com algumas distorções sociais, isto é, solucionar menores conflitos levados ao judiciário. Conforme os ensinamentos de Rocha, $(2014$, p. 4): "[...] foram criados no Rio Grande do Sul, no início da década de 80 , os Conselhos de Conciliação e Arbitramento, que "não tinham existência legal, não tinham função judicante, com juízes improvisados, atuando fora do horário de expediente forense".

Seguindo-se esta ordem, no Brasil foi editada a Lei n. 0 7.244/84 (Juizado Informal de Conciliação - JIC), criando-se, assim, os Juizados Especiais de Pequenas Causas, no intuito de facilitar e acelerar o acesso à justiça aos menos favorecidos. Segundo os ensinamentos de Cunha ${ }^{1}$ (1997, p. 15), "A lei dos Juizados Especiais de Pequenas Causas significou autêntica revolução no processo civil brasileiro. Inovou e reformulou conceitos até então consagrados no Código de Processo Civil."

Posteriormente, em 1988, foi promulgada uma nova Constituição Federal e com inspiração na lei supracitada, previu a criação de Juizados Especiais em seu artigo 98, I:

Art. 98. A União, no Distrito Federal e nos Territórios, e os Estados criarão:

I - juizados especiais, providos por juízes togados, ou togados e leigos, competentes para a conciliação, o julgamento e a execução de causas cíveis de menor complexidade e infrações penais de menor potencial ofensivo, mediante os procedimentos oral e sumariíssimo, permitidos, nas hipóteses previstas em lei, a transação e o julgamento de recursos por turmas de juízes de primeiro grau. (BRASIL, 1988)

Desta forma, em observância à exigência constitucional, uma nova legislação fora editada, Lei n. 9.099 de 26 de setembro de 1995 (Lei dos Juizados Especiais Cíveis e Criminais), regulando os Juizados Especiais estaduais e extinguindo a lei dos Juizados Especiais de Pequenas Causas, passando a comportar as pequenas causas e as causas menos complexas.

Neste sentido, ensina Soares (1996, p. 23):

Eis que surge uma nova Constituição Federal de 1988, trazendo no seu bojo inúmeros avanços de indiscutível alcance social. Por ela, a União, no Distrito Federal e nos Territórios, e os Estados, como permite o inciso I do art. 98, ficaram autorizados a criar os seus Juizados Especiais. Tal preceito representou mais uma tentativa do Constituinte brasileiro de oferecer ao cidadão, em especial ao mais pobre, meios de acesso à Justiça com a necessária simplicidade, celeridade, brevidade e, acima de tudo, com a economia de gastos, este dispêndio que impregna a Justiça brasileira.

Assim, o objetivo principal dos Juizados Especiais foi especialmente a democratização da justiça, de forma a combater a litigiosidade contida e permitir que as causas com baixo valor econômico - que anteriormente nunca haviam chegado ao judiciário, uma vez que acabaria gerando maiores custos à parte - pudessem, a partir de então, ser apreciadas.

\footnotetext{
${ }^{1}$ Juiz de Direito do Paraná; Professor Assistente de Direito Processual Civil da Faculdade de Direito da Universidade Estadual de Ponta Grossa; ExProfessor da Escola Superior da Magistratura do Paraná; Mestre em Direito das Relações Sociais-Sub-área de Direito Processual Civil pela PUC-SP; Doutorando pela Universidade Federal do Paraná.

Colloquium Socialis, Presidente Prudente, v. 01, n. Especial 2, Jul/Dez, 2017, p.298-304. DOI: 10.5747/cs.2017.v01.nesp2.s0152
} 
Abordando o assunto, Marinoni, Arenhart e Mitidiero (2015, p. 291) disciplinam:

Imagine-se utilizar o processo tradicional para a cobrança de uma dívida de $\mathrm{R} \$ 100,00$ (cem reais). Ninguém em sã consciência proporia uma demanda cível de conhecimento para atender a esta pretensão condenatória, haja vista o custo do processo, a demora natural da solução do litígio - que poderia retirar completamente a vantagem pleiteada - e tantos outros obstáculos que comprometeriam a utilidade da tutela jurisdicional no caso concreto.

Mais tarde, foram postas a viger outras novas leis, quais sejam, a Lei $\mathrm{n} .010 .259$ de 12 de julho de 2001 (Juizado Especial Federal) e a Lei n.o 12.153 de 22 de dezembro de 2009 (Juizado Especial da Fazenda Pública), as quais se dedicaram a cuidar das causas sem complicações de ordem previdenciária e tributária, sendo baseadas nos princípios da informalidade, simplicidade, oralidade, economia processual e celeridade, sustentando, como principal escopo, a conciliação ou transação - uma composição amigável, portanto.

Assim, é de se enxergar, grande parte das pretensões no Judiciário são conciliáveis com os Juizados Especiais Cíveis, haja vista ausentar o abuso de formalidades bem como burocratizações; isto se torna mais praticável, permitindo que o Estado proporcione, à sociedade, a solução mais acelerada à lide.

\section{PRINCÍPIOS ORIENTADORES DOS JUIZADOS ESPECIAIS CÍVEIS}

Inicialmente, antes da explanação peculiar dos princípios norteadores dos Juizados Especiais Cíveis, cumpre salientar, os princípios e garantias constitucionais vigoram também nos Juizados Especiais Cíveis - como o devido processo legal, ampla defesa, contraditório, isonomia, entre outros -, uma vez que têm extrema importância no ordenamento jurídico brasileiro.

Segundo Alexy (apud BARBOSA; BONIN, 2015, p. 632), "princípios são mandamentos de otimização, devendo os mesmos ser aplicados na máxima medida possível de acordo com as circunstâncias fáticas e jurídicas".

No que se refere aos Juizados Especiais Cíveis, os princípios orientadores encontram-se elencados no artigo 2 o da Lei n.o 9.099/1995², quais sejam, oralidade, simplicidade, informalidade, economia processual e celeridade. Ressalta-se, a Lei n.o 9.099/1995 foi uma das primeiras legislações a trazer, expressamente, seus princípios básicos. Não obstante, tais princípios são aplicáveis também aos Juizados Especiais Federais e aos Juizados Especiais da Fazenda Pública.

\section{PRINCÍPIO DA ORALIDADE}

O princípio da oralidade, além de constar no artigo $2^{\circ}$ da Lei n. 9 9.099/1995 como um dos princípios orientadores dos Juizados Especiais Cíveis, conceitua-se também como sendo um critério, uma vez que, por meio deste, a inicial ${ }^{3}$, a defesa ${ }^{4}$ e demais atos processuais podem ser dirigidos ao juiz competente de forma oral.

A regra é que os atos processuais orais devem prevalecer sobre os escritos. Contudo caberá às partes decidirem sobre a forma oral ou escrita dos atos, haja vista não se tratar de imposição obrigatória da lei. Nos ensinamentos de Marinoni, Arenhart e Mitidiero (2015, p. 293):

[...] nota-se das claras disposições da Lei dos Juizados Especiais a nítida orientação no sentido de que o processo se desenvolva de maneira

\footnotetext{
${ }^{2}$ Art. 2o. O processo orientar-se-á pelos critérios da oralidade, simplicidade, informalidade, economia processual e celeridade, buscando, sempre que possível, a conciliação ou a transação.

${ }^{3}$ Art. 14. O processo instaurar-se-á com a apresentação do pedido, escrito ou oral, à Secretaria do Juizado.

${ }^{4}$ Art. 30. A contestação, que será oral ou escrita, conterá toda matéria de defesa, exceto arguição de suspeição ou impedimento do Juiz, que se processará na forma da legislação em vigor.

Colloquium Socialis, Presidente Prudente, v. 01, n. Especial 2, Jul/Dez, 2017, p.298-304. DOI: 10.5747/cs.2017.v01.nesp2.s0152
} 
absolutamente oral, minimizando-se a burocratização e acelerando-se, consequentemente, a solução da controvérsia.

Assim, a principal finalidade deste princípio é acelerar o procedimento dos Juizados, sem delongas, reduzindo-se, a termo, apenas as matérias indispensáveis à solução da demanda ( $v$. $g$., a citação e a sentença, conforme o artigo 13, § $3^{\circ}$, da Lei n.ㅇ 9.099/95), evitando-se longas petições.

\section{PRINCÍPIO DA SIMPLICIDADE}

Pelo princípio da simplicidade, o procedimento dos Juizados Especiais deve ser simples em comparação à Justiça Ordinária, para que se possa facilitar o entendimento das partes. Assim, segundo Rossato (2012, p. 19), "A simplicidade é marca dos Juizados Especiais, o que desonera o procedimento da complexidade própria do procedimento ordinário."

O artigo 13 da Lei $n$. 9.099/1995 expressa a finalidade do princípio da simplicidade: "Os atos processuais serão válidos sempre que preencherem as finalidades para as quais forem realizados, atendidos os critérios indicados no artigo 2얼 desta Lei." (BRASIL, 1995)

O princípio da simplicidade encontra acolhimento nos princípios da informalidade e celeridade, por não ser exigida a complexidade que norteia a Justiça Comum; os atos processuais dentro nos Juizados poderão - e devem - ser menos formais e, por conseguinte, mais rápidos.

Acrescenta-se ainda, o artigo 46 da Lei n. 9 9.099/1995 engloba, implicitamente, o princípio da simplicidade, haja vista dispensar-se o relatório nas sentenças. No mais, nesse mesmo sentido dispõe o enunciado 92 do FONAJE 5 .

Portanto, observa-se, a principal função do princípio da simplicidade é a subsunção da lei ao caso concreto, visando, sempre, a eficácia, uma vez que, se assim não fosse, seria deixado de lado a pretensão da própria Lei direcionada à celeridade procedimental.

\section{PRINCÍPIO DA INFORMALIDADE}

O princípio da informalidade, por sua vez, apresenta-se como uma das principais distinções entre os Juizados Especiais Cíveis e a Justiça Comum Ordinária, haja vista, nesta última, a formalidade ser um dos requisitos extrínsecos exigidos ao exercício do direito de ação. Rossato (2012, p. 19), por meio de seus ensinamentos, explica:

O princípio da informalidade apresenta-se como a potencialização de outro princípio, o da instrumentalidade das formas. A busca pela Justiça e a preocupação com a matéria de fundo devem ser o norte de todo e qualquer procedimento, seja ele ordinário, seja sumaríssimo.

Observa-se, portanto, dentro do órgão em questão a forma é irrelevante, lavando-se em consideração o ato propriamente dito, desde que alcançada a finalidade para a qual se destina.

Diante do exposto, é possível concluir, o objetivo deste princípio é dispensar a complexidade exigida por meio das formas, a fim de tonar mais prático e rápido o resultado almejado pelas partes componentes da relação jurídica. Isto porque os atos processuais nos Juizados Especiais não devem estar atrelados à formalidade extravagante, visando à celeridade das decisões. Desta forma, petições e sentenças devem conter somente a essência do ato que se busca praticar.

\section{PRINCÍPIO DA ECONOMIA PROCESSUAL}

O princípio da economia processual busca uma maior efetividade processual, com a mínima realização possível de atos. Ademais, tal princípio tem correlação com os princípios da

\footnotetext{
${ }^{5}$ ENUNCIADO 92 - Nos termos do art. 46 da Lei no 9099/1995, é dispensável o relatório nos julgamentos proferidos pelas Turmas Recursais (XVI Encontro - Rio de Janeiro/RJ).
} 
simplicidade e informalidade, uma vez que o fato da realização dos atos processuais ser mais simples e menos burocrática, consequentemente, gera uma economia processual, se comparado ao procedimento da Justiça Comum. Neste contexto, lecionam Marinoni, Arenhart e Mitidiero (2015, p. 296): “Minimizando-se o procedimento tendente ao oferecimento da prestação jurisdicional, ganha-se de forma menos complicada uma resposta jurisdicional mais barata e rápida, o que é fundamental para estimular o acesso à Justiça."

Portanto sua principal finalidade é a redução do número de atos processuais praticados dentro de um mesmo processo. Daí o motivo pelo qual o legislador deixou expresso na Lei que um ato só será considerado nulo se não alcançar a sua finalidade, conforme já citado no princípio anterior.

Acrescenta-se, a concentração dos atos processuais em uma única audiência, conforme o disposto nos artigos 21 e 27 da Lei dos Juizados Especiais Cíveis, é um grande exemplo de economia processual, uma vez que permite a realização de um maior número de atos de uma única vez, de forma a agilizar o percurso de tempo e economizar os gastos dentro do processo.

Vale ressaltar, pelo princípio da gratuidade da justiça, em $1^{\circ}$ grau nos Juizados Especiais Cíveis, a parte litigante será isenta do pagamento de custas processuais e honorário advocatícios, representando-se também o princípio em questão, conforme disposto nos artigos 54 e 55 da Lei n. 9 9.099/1995, exceto nos casos em que restar configurada a litigância de má-fé.

Assim, observa-se, este princípio visa a buscar o melhor resultado na aplicação do direito, com o mínimo de atividades processuais. Além de ser mais prático e ágil, será também mais econômico às partes formadoras da relação jurídica.

\section{PRINCÍPIO DA CELERIDADE}

O Princípio da celeridade corresponde a um direito fundamental previsto na Constituição Federal ${ }^{6}$. Com a celeridade os atos processuais tendem a ser realizados de forma ágil, evitando-se protelações. Segundo Santos e Chimenti (2010, p. 57), "Já no ato do ajuizamento da ação o autor sai intimado da audiência e, se for o caso, da data e local para comparecimento a perícia".

Ademais, a Lei dos Juizados Especiais Cíveis possui, implicitamente, dentro de vários dispositivos, o princípio da celeridade, como, por exemplo, o artigo 17, o qual dispõe: "Comparecendo inicialmente ambas as partes, instaurar-se-á, desde logo, a sessão de conciliação, dispensados o registro prévio de pedido e a citação". Outro grande exemplo é a concentração de vários atos em uma única audiência, conforme o disposto nos artigos 28 e $29^{7}$.

Acrescenta-se, o princípio da celeridade é dependente dos demais princípios já citados anteriormente, haja vista o fato dos atos processuais ser mais simples, informais e econômicos, agilizando-se o processo no todo.

Assim, tem-se em vista, diferentemente do procedimento ordinário adotado pela Justiça Comum, o Juizado Especial Cível adota o procedimento sumaríssimo, uma vez que, por tratar-se de causas menos complexas, a resolução tende a ser mais rápida. No mais, é uma vertente da economia processual, pois quanto mais simples os atos, mais rapidamente será alcançado o resultado pretendido.

\section{CONCLUSÃO}

\footnotetext{
${ }^{6}$ Artigo $5^{\circ}$, LXXVIII, da Constituição Federal: "a todos, no âmbito judicial e administrativo, são assegurados a razoável duração do processo e os meios que garantam a celeridade de sua tramitação". (BRASIL, 1988)

${ }^{7}$ Art. 28. Na audiência de instrução e julgamento serão ouvidas as partes, colhida a prova e, em seguida, proferida a sentença.

Art. 29. Serão decididos de plano todos os incidentes que possam interferir no regular prosseguimento da audiência. As demais questões serão decididas na sentença.

Parágrafo único. Sobre os documentos apresentados por uma das partes, manifestar-se-á imediatamente a parte contrária, sem interrupção da audiência.

Colloquium Socialis, Presidente Prudente, v. 01, n. Especial 2, Jul/Dez, 2017, p.298-304. DOI: 10.5747/cs.2017.v01.nesp2.s0152
} 
Conclui-se, a criação dos Juizados Especiais foi nitidamente um grande avanço para a Justiça brasileira, uma vez que o intuito do legislador, ao disciplinar a criação deste órgão, foi, especialmente, a democratização da justiça, permitindo-se que as causas, ainda que consideradas de baixo valor econômico, pudessem ser apreciadas pelo Poder Judiciário.

Hodiernamente, a finalidade dos Juizados Especiais Cíveis continua sendo a mesma, qual seja, a celeridade nos litígios surgidos no dia a dia, julgando causas de menor complexidade ou, mesmo que complexas, com valor vil economicamente, não comprometendo a pretensão da parte, facilitando, a toda pessoa, o acesso à justiça, já que, além de promover a prestação jurisdicional ágil, também desobriga os postulantes de densas despesas processuais, bem como verbas honorárias à parte vencida, em primeira instância.

Ademais, em relação aos os princípios norteadores dos Juizados Especiais Cíveis, estes devem caminhar juntos, pois, consequentemente, um acaba gerando o outro. Assim, o objetivo de todos esses princípios é justamente alcançar a finalidade para a qual os Juizados Especiais Cíveis se destinam, qual seja, possibilitar o acesso à justiça de forma mais simples, informal, econômica e, principalmente, célere.

Finalmente, o desdobramento do tema fez-se necessário não somente como relevância jurídica para os operadores do direito, mas também como relevância social, destacando-se a origem e a principiologia dos Juizados Especiais Cíveis.

\section{REFERÊNCIAS}

ARENHART, S. C.; MITIDIERO, D.; MARINONI, L. G. Novo curso de processo civil. v. 2. São Paulo: Revista dos Tribunais, 2015.

. Novo curso de processo civil. v. 3. São Paulo: Revista dos Tribunais, 2015.

BARBOSA, R. V. M.; BONIN, N. M. M. A nova teoria geral dos recursos e as alterações no recurso inominado. Didier Jr. F. (coord). Juizados Especiais. v. 7. Salvador: JusPodivm, 2015.

BRASIL. Constituição da República Federativa do Brasil, de 5 de outubro de 1988. Vade Mecum. 4. ed. São Paulo: Saraiva, 2014.

BRASIL. Lei n. 9.099, de 26 de setembro de 1995. Dispõe sobre os Juizados Especiais Cíveis e Criminais e dá outras providências. Diário Oficial da União, Brasília, DF, 29 set. 1995. Disponível em: <http://www.planalto.gov.br/ccivil_03/leis/L9099.htm>. Acesso em: 10 dez. 2016.

CARVALHO, R. O. de; NETO, A. C. Juizados Especiais Cíveis e Criminais. 5. ed. Campo Grande: Contemplar, 2010.

CHIMENTI, Ricardo Cunha. Teoria e prática dos Juizados Especiais Cíveis estaduais e federais. 13. ed. São Paulo: Saraiva, 2012.

CHIMENTI, Ricardo Cunha; SANTOS, Marisa Ferreira dos. Juizados Especiais cíveis e criminais: federais e estaduais. 10. ed. São Paulo: Saraiva, 2012.

DINAMARCO, Cândido Rangel. Manual dos Juizados Especiais Cíveis. 2. ed. São Paulo: Malheiros Editores, 2001. 
ENCONTRO NACIONAL DE ENSINO, PESQUISA E EXTENSÃO DA UNOESTE - ENEPE, 2016, Presidente Prudente - SP. Os impactos do novo CPC no sistema recursal dos Juizados Especiais Cíveis. Universidade do Oeste Paulista, 2016.

ROCHA, Felippe Borring. Manual dos Juizados Especiais Cíveis estaduais. 7. ed. São Paulo: Atlas, 2014.

SILVA ROGERIO, T. F. Principais impactos do novo CPC no sistema recursal dos Juizados Especiais Cíveis. 2017. 59 f. Trabalho de Conclusão de Curso (Bacharelado) - Universidade do Oeste Paulista, Presidente Prudente - SP.

ROSSATO, Luciano Alves. Sistema dos Juizados Especiais: análise sob a ótica civil. São Paulo: Saraiva, 2012.

SOARES, Nildomar da Silveira. Juizado Especial Cível: a justiça na era moderna. 3. ed. São Paulo: LTr, 1996. 